From the American Academy of Family Physicians

Ann Fam Med 2005;3:472-473. DOI: 10.1370/afm.397.

\section{AAFP'S POLITICAL ACTION COMMITTEE ADDS TO FAMILY PHYSICIANS' VOICE IN WASHINGTON}

Family physicians have a new tool for voicing their positions on everything from Medicare physician payment to medical liability reform to incentives for providing health care to the underserved.

That tool: FamMedPAC, the AAFP's new federal political action committee. Since its June launch,

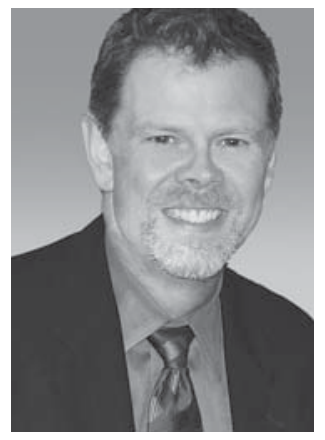

FamMedPAC has retained Mark Cribben, JD, as its director and garnered more than $\$ 70,000$ in donations. The PAC board has set a goal of raising and contributing $\$ 1$ million in this election cycle. The donations will be allocated to political candidates who meet the PAC's criteria for family medicine's support.

Approved by the 2004

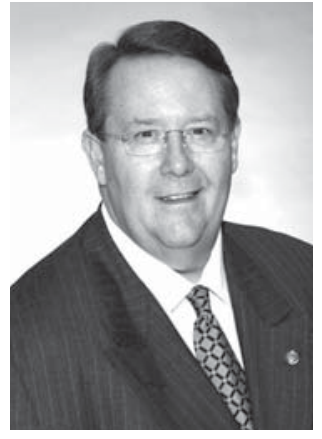

Congress of Delegates, FamMedPAC will offer several benefits, according to PAC Board Chair, Michael Fleming, MD, of Shreveport, La.

"The chief benefit is ensuring that your specialty is adequately represented when Congress addresses long-term issues such as skyrocketing medical liability costs, unfair reimbursement rates, reduced physician training or the growing number of uninsured," he said in an introductory letter about FamMedPAC to Academy members. "Without a consistent, concerted voice that compels politicians to listen, your views may not be heard."

FamMedPAC donors also will receive insider information on political dealings influencing family medicine, potential candidates, and indications of which candidates deserve FamMedPAC support.

"Other benefits to you are intangible, but quite real," said Fleming in his letter. "By joining FamMedPAC, you will have the ability to become more actively involved in the legislative and political action process. Through a greater understanding of the issues, you can become more comfortable initiating person-to-person contact with your elected officials and you strengthen your relationship with your representative and senators."

Moreover, according to Cribben, family physicians can make their political contributions stretch farther via the PAC. Federal law limits individual donations to a political candidate to $\$ 2,100$ per election cycle. But AAFP members can contribute up to $\$ 5,000$ per year to FamMedPAC.

And the PAC can combine the donations from AAFP members to make even larger contributions to candidates who deserve the support of family medicine, said Cribben.

As a result, family medicine will reap several benefits, including:

- Opportunities to help lawmakers understand the implications of their decisions on issues, such as physician payment, family medicine training, and access to health care coverage

- The ability to disseminate political information to AAFP membership without jeopardizing the Academy's tax-exempt status

- A tangible method of using family physicians' collective clout to hold federal lawmakers accountable for their legislative actions

"And it will encourage members to get involved," said Cribben. "We encourage members to get in touch with me or PAC board members and express their opinions about candidates."

Board members will use several criteria-including whether the candidates are family physicians, their leadership position in Congress or membership on important legislative committees, and their voting records and positions on issues related to priorities of family physicians and their patients_-for identifying federal candidates to receive FamMedPAC support.

"Another consideration may be the difficulty of the candidate's race," said Cribben. For example, the board may provide more support to friendly candidates who face difficult races.

Like all groups that provide information and feedback to lawmakers, the AAFP and its sister organizations have a solid grassroots program through action alerts and the key contact program. Most recently, both effectively communicated family medicine's position on federal funding for primary care education through Section 747 of Title VII of the Public Health Service Act. As a result of those efforts, the Senate voted to appropriate $\$ 90$ million for Title VII, despite House and Bush administration efforts to zero out federal support.

FamMedPAC will augment those efforts with direct political involvement, according to Cribben. 
The PAC began accepting donations online in August. The FamMedPAC Web site directs members to a password-protected page that will provide information about the committee's philosophy, goals, and current activities. Members then can click to a contribution page.

The PAC will offer contributors several options, said Cribben.

"The site will allow online credit card contributions, and we will accept contributions by cash, check and credit card at meetings throughout the year," he said. "We also give members who contribute by credit card the option of giving through periodic, automatic payments."

For more information about FamMedPAC, go to http://www.aafp.org/x34131.xml.

Leslie Champlin AAFP News Department

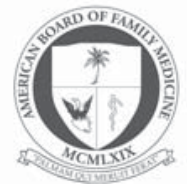

From the American

Board of Family Medicine

Ann Fam Med 2005;3:473-474. DOI: 10.1370/afm.398.

\section{LISTENING TO THE DIPLOMATES: PHYSICIANS' FEEDBACK ON SELF- ASSESSMENT MODULES}

The Self-Assessment Module (SAM) is an integral part of the ABFM's Maintenance of Certification for Family Physicians (MC-FP) process as well as an important learning opportunity. Contrary to what some may think, the SAMs are not tests, but rather self-evaluations and self-teaching experiences. A SAM consists of 2 parts: a knowledge assessment and a clinical simulation. Once a Diplomate completes the knowledge assessment portion for the first time, the missed questions will appear on second and subsequent tries with both references and critiques, making the SAM much more of a learning process than any type of examination. Whenever a physician completes a SAM, we solicit feedback regarding their experience to continually improve these modules. The results of this feedback for our first 4 modules reflect a strong positive response. In the areas of (1) relevance of information to clinical practice, (2) currency of information, (3) usefulness of information, and (4) overall value of the module, the average ratings fall at 5.4 on a 6 point scale (Figures 1-4).

Perhaps the most important feedback indicator is whether the information relayed in these educational modules effects positive outcomes by improving prac-
Figure 1. Physicians' rating of the hypertension self-assessment module.

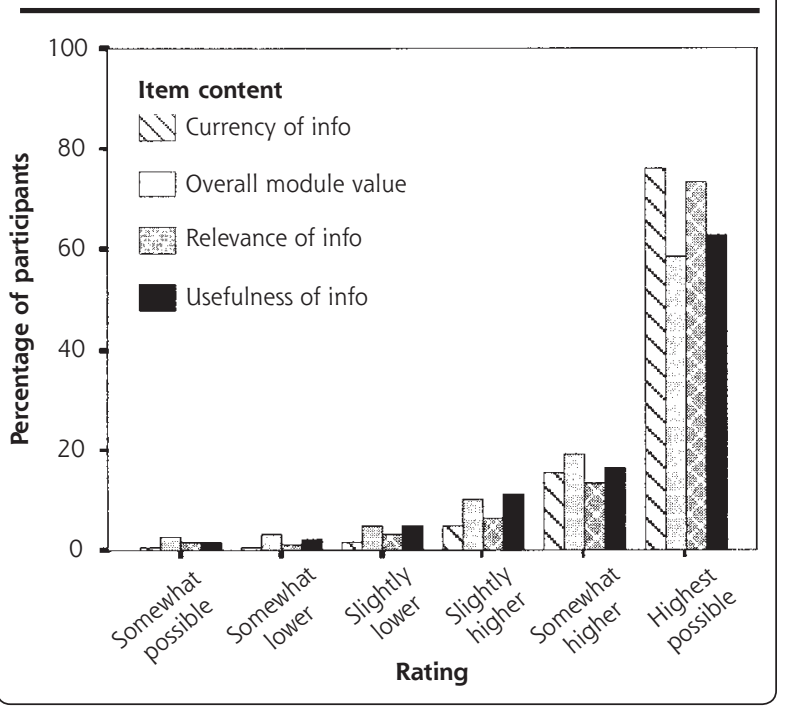

Figure 2. Physicians' rating of the coronary artery disease self-assessment module.

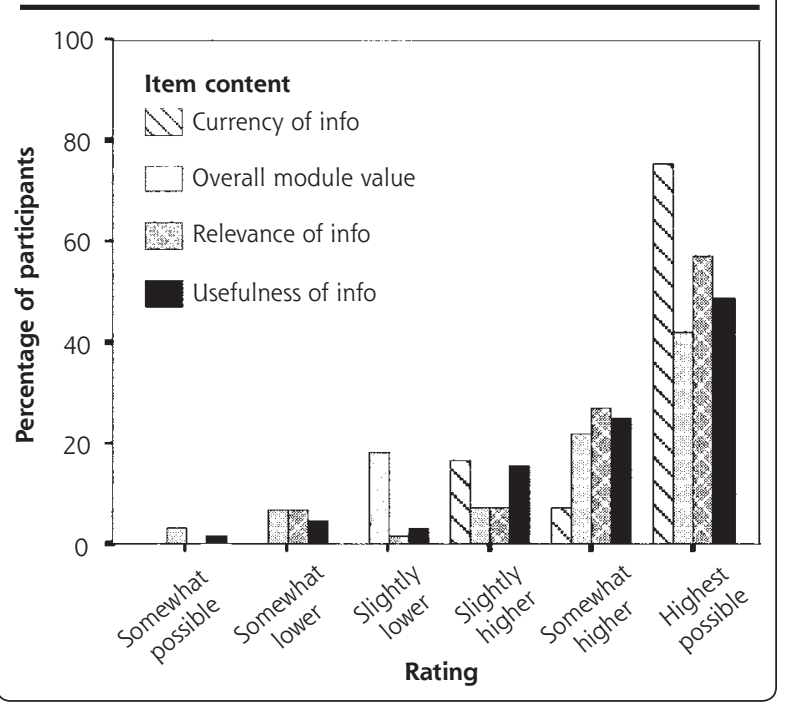

tice. In the case of the first 2 health topics offered in 2004, for which we have at least 1 year's record of physician evaluation, $54 \%$ of those taking the diabetes module indicated that they would change their practice as a result of participating. Ninety percent of those physicians volunteered written comments describing what changes they would make. For the hypertension module these values were within $1 \%$ of the diabetes module (nearly identical), providing a strong suggestion that both are high-quality educational materials.

These results bear out the goals established in the development of the SAMs as the primary facet of Part II of MC-FP, Self-Assessment and Lifelong Learning, 